\title{
Yield Comparison for Synthetic-derived Bread Wheat Genotypes with Different Water Uptake Abilities under Increasing Soil Water Deficits
}

\author{
M.N. INAGAKI ${ }^{1,2} *$ M. MORI ${ }^{1,2}$ and M.M. NACHIT ${ }^{1}$ \\ ${ }^{1}$ International Center for Agricultural Research in the Dry Areas (ICARDA), P.O. Box 5466, Aleppo, Syria \\ ${ }^{2}$ Japan International Research Center for Agricultural Sciences (JIRCAS), Tsukuba, Ibaraki 305-8686, Japan
}

(Received 2 October 2009; accepted 22 June 2010)

\begin{abstract}
The drought stress in the rain-fed regions of West Asia and North Africa strongly depends on residual soil water available for the reproductive plant growth. The water uptake ability (i.e. water consumption per unit dry matter per day) of three synthetic-derived bread wheat genotypes, SYN-8, SYN-10 and SYN-15, and their parental variety Cham 6 were examined under controlled conditions. In addition, yield performance was compared under one artificial environment with supplemental irrigation and ten rain-fed environments at two locations over five cropping seasons. Large differences were found in water uptake ability among the four wheat genotypes; SYN-8 had the highest and SYN-10 the lowest ability. These differences were reflected in decrease of soil water content and increase of leaf temperature after irrigation. Under field conditions of supplemental irrigation, there were no significant differences in grain yield among genotypes Cham 6, SYN-8 and SYN-10; however, SYN-15 had lower grain yield due to low harvest index. Significant differences of the grain yield were found between SYN-8 and SYN-10 grown in rain-fed conditions. Lower water uptake ability was associated with higher grain yield; this speculates that intensive extraction of water from soil during vegetative growth might increase biomass production, but leave inadequate available soil moisture for reproductive growth and grain production. The balancing of water consumption by plants with stored soil moisture over the whole growing period is a major attribute of drought adaptation in these synthetic-derived wheat genotypes.
\end{abstract}

Keywords: synthetic wheat, soil water, water uptake, leaf temperature, drought, adaptation

\section{Introduction}

In the rain-fed regions of West Asia and North Africa (WANA), limited rainfall and frequent unpredictable drought result in low and fluctuating wheat production, whereas supplemental irrigation allows high and stable production in the same regions (Marathée and Gomez-MacPherson 2001). Global climate fluctuations may increasingly affect limited water supplies and the use of scarce water in dry regions. Drought tolerance is therefore a major objective in wheat breeding for enhancing adaptation to climate change. Breeding research on drought tolerance in wheat focuses extensively on use of alien genetic resources and development of screening methodology.

\footnotetext{
* Corresponding author; E-mail: m.inagaki@cgiar.org
} 
There have been recent studies on grain yield improvement in synthetic-derived bread wheat through incorporation of alien genes from wild relatives (Del Blanco et al. 2001; Dreccer et al. 2007; Inagaki et al. 2007; Trethowan and van Ginkel 2009). Drought tolerance estimated under water-limited conditions is a complex function strongly influenced by genetic variation and increasing stress by soil water deficit through evapotranspiration (Reynolds et al. 2007).

The growing season of wheat in WANA regions coincides with rainfall from November to May. Drought stress occurs mainly through decreasing soil water during March to May. Physiological understanding of drought tolerance makes the process of genetic improvement more efficient (Richards et al. 2002; Reynolds et al. 2007; Rebetzke et al. 2009). More water consumption during early growth can result in a lack of the water needed to support the larger biomass at a later stage. Final grain formation is subject to the balance between plant water consumption and available stored soil water. Water uptake (or extraction) has been studied in relation to root growth (Proffitt et al. 1985; Meyer et al. 1990; Asseng et al. 1998; Xue et al. 2003), whereas genetic improvement for drought tolerance has been reviewed in terms of adaptation to drought (Reynolds et al. 2006). Water uptake ability may be critical in controlling adaptation of wheat to soil water deficits. It is, however, not clear how synthetic-derived wheat genotypes consume soil water and respond to increasing water deficit stress.

In this study, the yield performance of four wheat genotypes including three synthetic-derived genotypes of different water uptake abilities was compared under highly variable and contrasting rainfall conditions.

\section{Materials and Methods}

\section{Water consumption of four wheat genotypes under controlled conditions}

Water consumption was compared among four genotypes of synthetic-derived bread wheat (Triticum aestivum L.), SYN-8, SYN-10, SYN-15 and their parental variety Cham 6 having similar heading times. SYN-8, SYN-10 and SYN-15 were selected from a cross of Cham $6 / 3 /$ Haurani /Aegilops tauschii ig47259//Cham 6 (Inagaki et al. 2007). Three plants per wheat genotype were grown in potted soil (1075 g in dry weight) with three replications in a growth chamber with $22 / 10^{\circ} \mathrm{C}$ day/night, $80-50 \%$ relative humidity, 10 -h day-length and $250 \mu \mathrm{mol} \cdot \mathrm{m}^{-2} \cdot \mathrm{s}^{-1}$ light intensity. Potted soil was a mixture of field soil, sand and peat moss, with a permanent wilting point of $14.6 \%$, which was determined by weight at $-1500 \mathrm{kPa}$ of suction pressure. Pots were periodically irrigated to maintain soil water content (ratio in percent of water amount to dry soil weight) at $35-20 \%$ from germination to heading.

Water consumption through evapotranspiration was estimated by the decrease of pot weight after irrigation. Evaporation from soil surface was estimated by periodically weighing the pots without any wheat plants. Transpiration of wheat plants was expressed as the difference between water consumption of pots with plants (evapotranspiration) and without plants (evaporation). 
During the seven consecutive days after the flag-leaf stage, soil water contents were obtained by weighing pots, and at the same time thermal images of plants of the four genotypes were taken in the same frame using an infrared camera (Nippon Avionics, TVS-200), as described by Inagaki and Nachit (2008). At the flag-leaf and heading stages, separate sets of wheat plants were harvested and dried for aboveground biomass measurements.

\section{Agronomic performance of four wheat genotypes in field trials}

Seeds of Cham 6, SYN-8, SYN-10 and SYN-15 were sown in $10-\mathrm{m}^{2}$ field plots at a rate of $12 \mathrm{~g} \cdot \mathrm{m}^{-2}$. The experiment was laid out with three replications in a randomized complete block design at the Tel Hadya and Breda stations of the International Center for Agricultural Research in the Dry Areas (ICARDA), Syria, in late November for the five cropping seasons of 2004-2008. Annual rainfall varied widely across years and locations (400-223 $\mathrm{mm}$ at Tel Hadya and 303-174 mm at Breda). Soils from the Tel Hadya and Breda stations were classified as fine clay and clay loam (Ryan et al. 1997), with permanent wilting points with ranges of $33.3-26.4 \%$ and $24.5-19.1 \%$ by weight, respectively. All wheat plots reached heading stage with differences of a few days in mid-April. After maturity in early June, wheat plants of $6 \mathrm{~m}^{2}$ per plot was harvested and agronomic data on plant height (culm length), aboveground biomass, grain yield and harvest index were collected after natural drying (residual water content of 6-5\%) in field.

In the 2008 cropping season at Tel Hadya, supplemental irrigation was used to supply an estimated regional evapotranspiration (equivalent to crop water requirement) of 420 $\mathrm{mm}$ (Zhang et al. 1998) during the period from germination to heading. Water contents of soil cores ( $7-\mathrm{cm}$ diameter) at $30-\mathrm{cm}$ intervals over $0-90 \mathrm{~cm}$ depth were monthly measured by weight in randomly selected three plots from germination to maturity. In addition, both dry root weight and soil water content were obtained for the four genotypes at heading stage. Statistical analyses used Tukey's multiple range test derived from the analyses of variance to compare the wheat genotype means.

\section{Results}

\section{Differences in water uptake abilities of four wheat genotypes}

Water consumption through transpiration and soil evaporation, and biomass production during the period from germination to heading are shown in Table 1. For all genotypes, the water consumption from flag-leaf to heading was greater than from germination to flag-leaf, since plants expanded larger leaves in the later stage.

There were large variations in both water consumption and water uptake ability (i.e. water consumption per unit dry matter per day) among genotypes; SYN-8 had the highest and SYN-10 the lowest. The higher water uptake of SYN-8 was reflected in more rapid decrease in soil water content after irrigation at the flag-leaf stage than for other genotypes (Fig. 1). The infrared thermographs indicated that, in comparison with the other genotypes, SYN-8 had lower leaf temperature one day after irrigation, and in contrast, in- 
creased temperature three days after irrigation (Fig. 2), probably as the soil of SYN-8 became drier than the others.

Table 1. Water consumption and biomass production through transpiration and soil evaporation during the period from germination to heading in four wheat genotypes grown in potted soil

\begin{tabular}{|c|c|c|c|c|c|c|}
\hline \multirow[t]{2}{*}{ Wheat genotype } & \multirow[t]{2}{*}{ Function } & \multicolumn{2}{|c|}{$\begin{array}{l}\text { Water consumption } \\
\left(\mathrm{g} \cdot \operatorname{pot}^{-1} \cdot \text { day }^{-1}\right)\end{array}$} & \multicolumn{2}{|c|}{$\begin{array}{l}\text { Biomass } \\
\left(\mathrm{g} \cdot \mathrm{pot}^{-1}\right)\end{array}$} & \multirow{2}{*}{$\begin{array}{l}\begin{array}{l}\text { Water uptake } \\
\left(\mathrm{g} \cdot \mathrm{g}^{-1} \cdot \mathrm{day}^{-1}\right)\end{array} \\
\begin{array}{c}\text { Flag-leaf } \\
\text { to heading }\end{array}\end{array}$} \\
\hline & & $\begin{array}{l}\text { Germination } \\
\text { to flag-leaf }\end{array}$ & $\begin{array}{l}\text { Flag-leaf } \\
\text { to heading }\end{array}$ & At flag-leaf & At heading & \\
\hline Cham 6 & Transpiration & $14.5^{\mathrm{b}}$ & $26.2^{\mathrm{b}}$ & $3.8^{\mathrm{a}}$ & $4.3^{\mathrm{a}}$ & $7.0^{\mathrm{a}}$ \\
\hline SYN-8 & Transpiration & $17.2^{\mathrm{c}}$ & $35.6^{\mathrm{c}}$ & $4.0^{\mathrm{a}}$ & $4.4^{\mathrm{a}}$ & $9.2^{\mathrm{bc}}$ \\
\hline SYN-10 & Transpiration & $12.1^{\mathrm{a}}$ & $21.9^{\mathrm{a}}$ & $3.5^{\mathrm{a}}$ & $4.0^{\mathrm{a}}$ & $6.4^{\mathrm{a}}$ \\
\hline SYN-15 & Transpiration & $15.4^{\mathrm{b}}$ & $36.8^{\mathrm{c}}$ & $4.5^{\mathrm{a}}$ & $5.4^{\mathrm{a}}$ & $8.3^{\mathrm{ab}}$ \\
\hline Potted soil & Evaporation & 23.3 & 20.2 & - & - & - \\
\hline
\end{tabular}

Numbers followed by the same superscript letter in each column are not significantly different at the probability of $\mathrm{P}<0.05$.

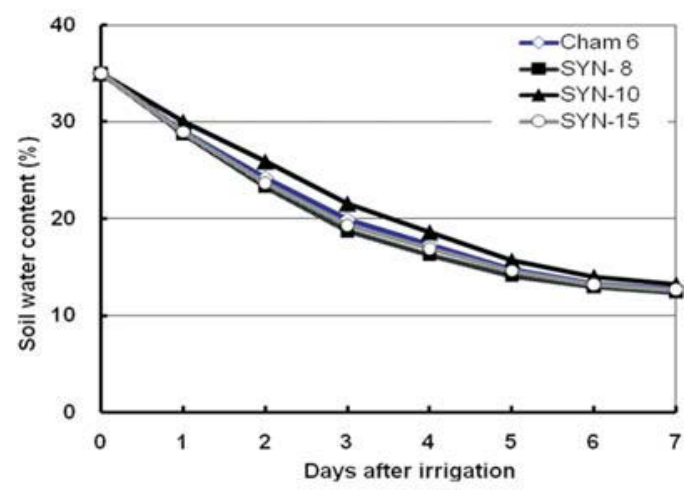

Figure 1. Soil water contents ( $\%$ by weight) after irrigation in the seven days after the flag leaf stage for four wheat genotypes grown in potted soil. LSD $(\mathrm{P}<0.05)=1.24 \%$

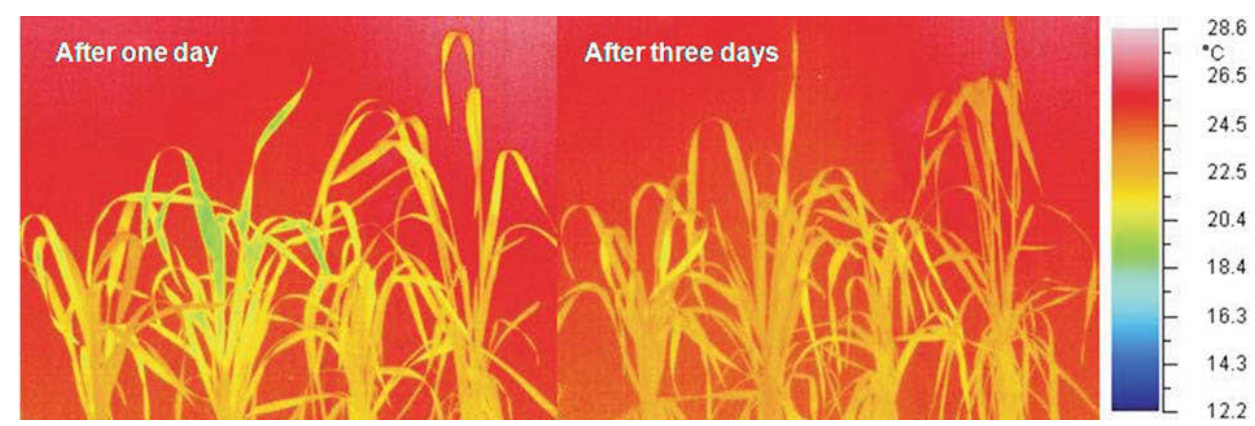

Figure 2. Infrared thermographs of four wheat genotypes (from left to right; Cham 6, SYN-8, SYN-10 and SYN-15), one day (left) and three days (right) after irrigation 


\section{Yield comparison of four wheat genotypes in field trials}

Soil water contents in wheat plots at Tel Hadya in the 2008 cropping season under supplemental irrigation and rain-fed conditions are shown in Figure 3. Wheat plants with supplemental irrigation of $209 \mathrm{~mm}$ received a total of water supply of $432 \mathrm{~mm}$ and were grown under favorable conditions fulfilled with a crop water requirement in these regions. Soil became wetter from the upper to deeper soil layers as water supply increased by rainfall and irrigation. Soil water content of the deepest $60-90 \mathrm{~cm}$ layer remained less than permanent wilting point under rain-fed conditions, but reached permanent wilting point by February under supplemental irrigation. All the soil moisture recharged during the wheat growth period was completely discharged through evapotranspiration by harvest time under both supplemental irrigation and rain-fed conditions. It was noted that actual soil moisture in field soil was not uniform, in particular, in upper 0-30 cm layer in the process of water recharge and discharge.

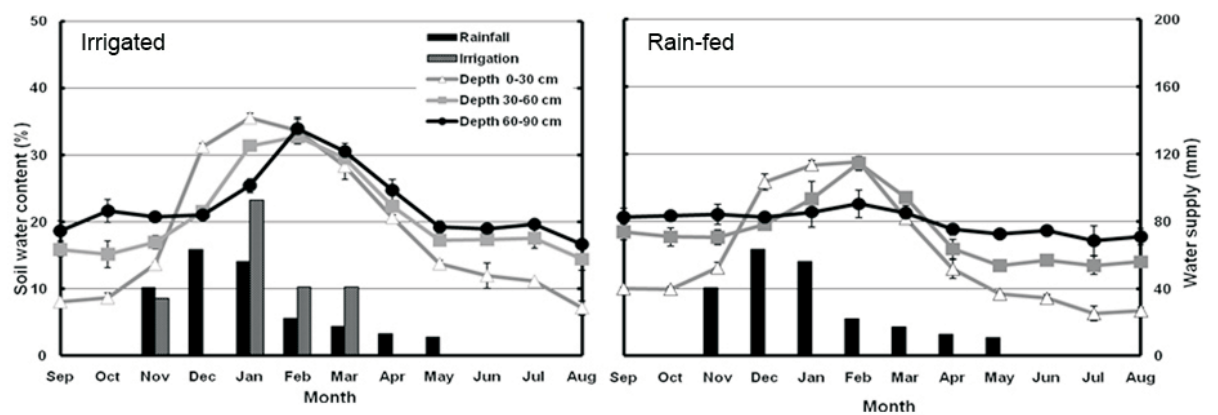

Figure 3. Soil water contents (\% by weight) in wheat plots under supplemental irrigation (left) and rain-fed (right) conditions at Tel Hadya in 2008 cropping season. Range bars indicate \pm standard deviations of the means

Under supplemental irrigation, the soil water content of SYN-10 plot at heading time was significantly higher than those of the other genotypes only at $0-30 \mathrm{~cm}$ depth (Table 2). Dry root weights (Table 3) indicated that root development was significantly depressed by soil water deficit; in addition, SYN-10 and SYN-15 had heavier total root weights than the other genotypes. Under rain-fed conditions, however, distinct differences were not found in both soil water content and root weight among the genotypes. Approximately $60 \%, 30 \%$ and $10 \%$ of the roots occurred at $0-30,30-60$ and $60-90 \mathrm{~cm}$ depth, respectively. Under supplemental irrigation, there were no significant differences in grain yield for Cham 6, SYN-8 and SYN-10, while SYN-15 had low grain yield (data not shown).

The means of four agronomic traits of the four wheat genotypes grown under ten rain-fed environments are compared in Table 4. The plant height of SYN-15 (a tall type) was greater than that of the other genotypes (short types). Variation of plant height was studied in the recombinant inbred lines derived from the crosses among these four wheat genotypes. The results suggested that two different semi-dwarfing genes were involved, one carried by SYN-15, and the other by Cham 6, SYN-8 and SYN-10 (data not shown). 


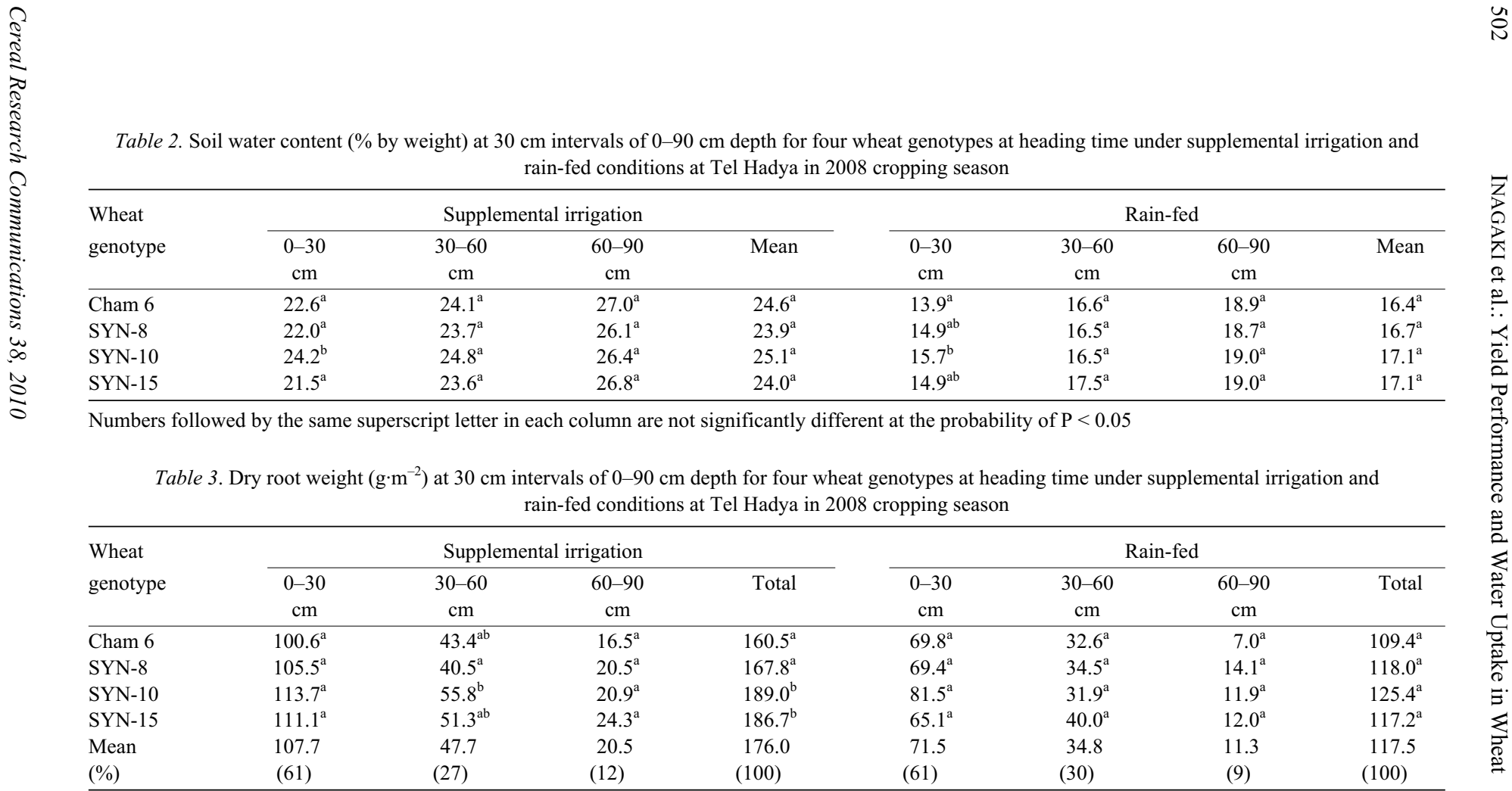

Numbers followed by the same superscript letter in each column are not significantly different at the probability of $\mathrm{P}<0.05$. 
Table 4. Means of four agronomic traits for four wheat genotypes grown under ten rain-fed environmental conditions

\begin{tabular}{lcccc}
\hline Wheat genotype & $\begin{array}{c}\text { Plant height } \\
(\mathrm{cm})\end{array}$ & $\begin{array}{c}\text { Biomass } \\
\left(\mathrm{g} \cdot \mathrm{m}^{-2}\right)\end{array}$ & $\begin{array}{c}\text { Grain yield } \\
\left(\mathrm{g} \cdot \mathrm{m}^{-2}\right)\end{array}$ & $\begin{array}{c}\text { Harvest index } \\
(\%)\end{array}$ \\
\hline Cham 6 & $44.5^{\mathrm{a}}$ & $785^{\mathrm{a}}$ & $195^{\mathrm{c}}$ & $20.9^{\mathrm{b}}$ \\
SYN-8 & $47.3^{\mathrm{a}}$ & $720^{\mathrm{a}}$ & $159^{\mathrm{b}}$ & $20.7^{\mathrm{b}}$ \\
SYN-10 & $47.4^{\mathrm{a}}$ & $766^{\mathrm{a}}$ & $205^{\mathrm{c}}$ & $23.5^{\mathrm{b}}$ \\
SYN-15 & $56.6^{\mathrm{b}}$ & $867^{\mathrm{a}}$ & $119^{\mathrm{a}}$ & $12.4^{\mathrm{a}}$ \\
\hline
\end{tabular}

Numbers followed by the same superscript letter in each column are not significantly different at the probability of $\mathrm{P}<0.05$.

The biomass production did not show genotypic differences although all genotypes decreased distinctly with a reduction in rainfall. Significant differences in grain yield were found among wheat genotypes, showing SYN-10 as the highest and SYN-15 as the lowest. Although no differences in harvest index were found among Cham 6, SYN-8 and SYN-10, SYN-15 showed the lowest harvest indexes among the genotypes across all environments.

\section{Discussion}

In this study, water uptake ability was used to express plant water consumption during growth under limited water supply. The alternative, water use efficiency (WUE), the ratio of biomass production relative to the water use for transpiration, has been intensively studied using carbon isotope discrimination (CID) as an indicator (Condon et al. 2002, 2004; Richards et al. 2002). Water uptake ability $\times$ growth duration is therefore the reciprocal of WUE, and relates directly to soil water availability, which in turn affects grain yield under water deficit stress. They can be expressed in the following terms:

Water uptake ability $=$ Plant water consumption $\times$ Biomass $^{-1} \times$ Growth duration $^{-1}$
$\begin{aligned} \text { Grain yield }= & \text { Plant water consumption } \times \text { Growth duration }{ }^{-1} \times \text { Water uptake ability } \\ & \times \text { Harvest index }\end{aligned}$

where plant water consumption through transpiration depends on the limited water supply from rainfall and supplemental irrigation under dry field conditions. Morphological growth traits are capable of changing the ratio of transpiration to evaporation (Richards et al. 2002). Growth duration in these dry regions is restricted to a small variation because of avoiding cold stress in early maturity and heat stress in late maturity. In the equation (2), two factors, water uptake ability and harvest index are major contributors to final grain yield under limited water supply.

There were significant differences in water uptake ability of the four genotypes, especially in comparison between genotypes SYN-8 and SYN-10, suggesting an association of lower water uptake ability (i.e. higher WUE) with higher grain yield, and vice versa. This association is similar to the relationship between WUE determined by CID and grain yield 
under water stress conditions (Condon et al. 2002). Water uptake ability can be simply estimated by measuring water consumption through transpiration at a critical stage from flag-leaf to heading. Infrared thermography for detecting leaf temperature can be also instantly and visually applied to distinguish differences in transpiration activity (Inagaki and Nachit 2008; Inagaki et al. 2009).

Variation in harvest index among the synthetic-derived wheat genotypes was critical in determining grain yield in an earlier study (Inagaki et al. 2007). This index is likely to be influenced by both semi-dwarfness and remobilization of stem assimilates under water deficit stress (Richards et al. 2002). Large variations for agronomic and physiological traits such as water uptake ability and harvest index might be expected in the genetic resources from wide crosses with wild relative species (Del Blanco et al. 2001; Dreccer et al. 2007).

Distinct differences in water consumption among wheat genotypes grown in potted soil did not clearly occur in soil water content at heading time under the field conditions. The field soil water might be mostly consumed by the heading time, not leaving available water even under supplemental irrigation. Intensive extraction of water from soil during vegetative growth increases biomass production under sufficient water supply; however, this can leave inadequate available soil moisture for reproductive growth under increasing water deficit stress, especially where rainfall is less than crop water requirement. As a part of biomass production, the root distribution and associated water uptake were mostly above the $60 \mathrm{~cm}$ depth of soil, as reported elsewhere (Asseng et al. 1998; Xue et al. 2003). A wheat genotype with lower water uptake ability, such as SYN-10 in comparison with SYN-8 with higher water uptake ability, left more soil moisture in upper soil layer at heading time, but nevertheless had more root development in total. Root development was also restricted to the shallow soil layers with more water. Vigorous root penetration might play an additional role in extracting water from subsoil deeper than $60 \mathrm{~cm}$. It remains still unclear in association between root development and biomass production in the soil with moisture gradient.

This study confirmed that the synthetic wheat genotypes, SYN-8 and SYN-15 with more water consumption, had significantly lower grain yields whereas SYN-10 and Cham 6 with less water consumption had higher grain yields under water deficit stress. Water uptake ability of wheat genotype affected soil moisture clearly in potted soil and partially in field soil, but did not explain how water uptake or water consumption was associated with final formation of grain yield through transpiration. In conclusion, balancing water consumption with stored soil moisture over the whole growth period is a major attribute of drought adaptation in these synthetic wheat genotypes. Breeding approaches for drought adaptation using water uptake ability require further physiological characterization and genetic analysis of transpiration efficiency using recombinant inbred lines differing in water uptake ability. 


\section{Acknowledgements}

This report is a contribution from a collaborative research project on "Evaluation of genetic resources and physiological analyses for enhancing drought tolerance in wheat germplasm (2006-10)" between ICARDA and JIRCAS.

\section{References}

Asseng, S., Ritchie, J.T., Smucker, A.J.M., Robertson, M.J. 1998. Root growth and water uptake during water deficit and recovering in wheat. Plant Soil 201:265-273.

Condon, A.G., Richards, R.A., Rebetzke, G.J., Farquhar, G.D. 2002. Improving intrinsic water-use efficiency and crop yield. Crop Sci. 42:122-131.

Condon, A.G., Richards, R.A., Rebetzke, G.J., Farquhar, G.D. 2004. Breeding for high water-use efficiency. J. Exp. Bot. 55:2447-2460.

Del Blanco, I.A., Rajaram, S., Kronstad, W.E. 2001. Agronomic potentials of synthetic hexaploid wheat-derived populations. Crop Sci. 41:670-676.

Dreccer, M.F., Borgognone, M.G., Ogbonnaya, F.C., Trethowan, R.M., Winter, B. 2007. CIMMYT-selected derived synthetic bread wheat for rainfed environments: Yield evaluation in Mexico. Field Crops Res. 100:218-228.

Inagaki, M.N., Valkoun, J., Nachit, M.M. 2007. Effect of soil water deficit on grain yield in synthetic bread wheat derivatives. Cereal Res. Commun. 35:1603-1608.

Inagaki, M.N., Nachit, M.M. 2008. Visual monitoring of water deficit stress using infra-red thermography in wheat. In: Appels, R. et al. (eds), Proceedings of the 11th International Wheat Genetics Symposium, Brisbane, Sydney University Press, 181. (URL: http://hdl.handle.net/2123/3452)

Inagaki, M., Mori, M., Nachit, M.M. 2009. Effect of a strobilurin-class fungicide on water use in synthetic bread wheat genotypes grown under increasing water deficit conditions. Cereal Res. Commun. 37:513-519.

Marathée, J.P., Gomez-MacPherson, H. 2001. Future world supply and demand. In: Bonjean, A. P., Angus, W. J. (eds), The World Wheat Book: A History of Wheat Breeding. Lavoisier Publishing, Paris, France. pp. $1107-1116$

Meyer, W.S., Tan, C.S., Barrs, H.D., Smith, R.C.G. 1990. Root growth and water uptake by wheat during drying of undisturbed and repacked soil in drainage lysimeters. Aust. J. Agr. Res. 41:253-265.

Proffitt, A.P.B., Berliner, P.R., Oosterhuis, D.M. 1985. A comparative study of root distribution and water extraction efficiency by wheat grown under high- and low-frequency irrigation. Agron. J. 77:655-662.

Rebetzke, G.J., Chapman, S.C., McIntyre, C.L., Richards, R.A., Condon, A.G., Watt, M., van Herwaarden, A.F. 2009. Grain yield improvement in water-limited environments. In: Carver, B.F. (ed.), Wheat: Science and Trade. Wiley-Blackwell, Iowa, USA. pp. 215-249.

Reynolds, M.P., Rebetzke, G., Pellegrineschi, A., Trethowan, R. 2006: Drought adaptation in wheat. In: Ribaut, J.-M. (ed.), Drought Adaptation in Cereals. Food Products Press, New York, USA. pp. 401-446.

Reynolds, M., Dreccer, F., Trethowan, R. 2007. Drought-adaptive traits derived from wheat wild relatives and landraces. J. Exp. Bot. 58:177-186.

Richards, R.A., Rebetzke, G.J., Condon, A.G., van Herwaadenet, A.F. 2002. Breeding opportunities for increasing the efficiency of water use and crop yield in temperate cereals. Crop Sci. 42:111-121.

Ryan, J., Masri, S., Garabet, S., Diekmann, J., Habib, H. 1997. Soils of ICARDA's agricultural experimental stations and sites: Climate, classification, physiological and chemical properties, and land use. ICARDA, Aleppo, $107 \mathrm{pp}$.

Trethowan, R., van Ginkel, M. 2009. Synthetic wheat-an emerging genetic resource. In: Carver, B. F. (ed.), Wheat: Science and Trade. Wiley-Blackwell, Iowa, USA. pp. 369-385.

Xue, Q., Zhu, Z., Musick, J.T., Stewart, B.A., Dusek, D.A. 2003. Root growth and water uptake in winter wheat under deficit irrigation. Plant Soil 257:151-161.

Zhang, H., Oweis, T., Garabet, S., Pala, M. 1998. Water-use efficiency and transpiration efficiency of wheat under rain-fed conditions and supplemental irrigation in a Mediterranean-type environment. Plant Soil 201:295-305.

Cereal Research Communications 38, 2010 